\title{
Seroprevalence, Detection of DNA in Blood and Milk, and Genotyping of Toxoplasma gondii in a Goat Population in Italy
}

\author{
Francesca Mancianti, Simona Nardoni, Carlo D'Ascenzi, Francesca Pedonese, \\ Linda Mugnaini, Filomena Franco, and Roberto Papini
}

Dipartimento di Scienze Veterinarie, Università di Pisa, Viale delle Piagge 2, 56100 Pisa, Italy

Correspondence should be addressed to Roberto Papini; rpapini@vet.unipi.it

Received 24 April 2013; Accepted 1 August 2013

Academic Editor: Yann Le Strat

Copyright ( 2013 Francesca Mancianti et al. This is an open access article distributed under the Creative Commons Attribution License, which permits unrestricted use, distribution, and reproduction in any medium, provided the original work is properly cited.

Toxoplasma gondii is the causative agent of a major zoonosis with cosmopolitan distribution and is known to be transmitted mainly by the ingestion of undercooked or raw animal products. Drinking unpasteurized goat's milk is a risk factor associated with human toxoplasmosis. However, very little is known about the excretion of DNA in goat milk. Aim of the present study was to determine the seroprevalence of T. gondii infection using a modified agglutination test (MAT), to detect T. gondii DNA by nested-PCR (nPCR) in samples of blood and milk from seropositive goats, and to genotype DNA isolates using 11 molecular markers in 127 adult lactating goats from 6 farms in Italy. Positive MAT results were found in $60.6 \%$ of goats while $13 \%$ of blood and milk samples from seropositive goats were positive to n-PCR. A kappa coefficient of 1 indicated a perfect agreement between blood and milk n-PCR. Genetic characterization of isolates revealed the occurrence of genotype III ( $n=7)$, genotype I $(n=1)$, and atypical genotypes with hints for genotype I $(n=2)$. Our results suggest that the risk of excretion of Toxoplasma tachyzoites might frequently occur in milk of seropositive goats testing positive to n-PCR on blood.

\section{Introduction}

Toxoplasmosis is a zoonotic infection caused by Toxoplasma gondii, an opportunistic protozoan belonging to the phylum Apicomplexa. The population structure of T. gondii is complex and shows distinct geographic patterns [1]. Approximately $90 \%$ of the T. gondii isolates from Europe and North America can be classified into three distinct clonal lineages (types I, II, and III strains) that differ remarkably in pathogenicity $[2,3]$. In addition, a fourth clonal lineage has been revealed in Nord America [4] and a higher genetic variability has been detected based on newer markers for genetic characterization [5]. The acute pathogenicity of $T$. gondii strains has been characterized in murine infections. The high pathogenicity of type I lineage is well represented by the commonly used laboratory strain $\mathrm{RH}$, since the primary inoculation of a single infectious organism into a mouse is the cause of death in $8-12$ days [2]. Instead, lineages II and III are considered low pathogenic in the mouse model [3]. T. gondii infections are widely prevalent in humans and animals worldwide [6]. Up to one-third of the human population in the world is chronically infected [6], and toxoplasmosis has been targeted one among the five parasitic diseases as priorities for public health action [7]. Human infections are primarily asymptomatic, but lymphadenopathy or ocular toxoplasmosis may occur in some patients. $T$. gondii infection in pregnant women may lead to abortion, stillbirth, or other serious consequences in newborns [8, 9]. In immune-compromised patients, toxoplasmosis can be fatal if not treated, and the reactivation of a latent infection can cause life-threatening encephalitis [8]. The parasite may be transmitted from a definitive to an intermediate host and vice versa, as well as between different definitive hosts or between different intermediate hosts [9]. Among food animals, sheep and goats are well-known sources of human infection [6]. Ingestion of undercooked goat meat 
and unpasteurized goat milk is considered source of human infections [6, 10]. Moreover, tachyzoites of $T$. gondii have been found in the milk of several species, including sheep, goats, and cows $[9,11]$. Excretion of tachyzoites in the milk of naturally infected goats was also reported [12], and infections in family clusters by consumption of raw goat milk have been documented $[13,14]$. Among food animals, goats appear to be more susceptible to clinical toxoplasmosis, and adult goats were reported to have died of acute toxoplasmosis [9]. The disease is a common cause of abortion and neonatal mortality in goats [6].

Serological screening in goats in Europe showed prevalence values of $15.2 \%$ [15] and $25.1 \%$ [16], further supporting the likelihood of infection by milk ingestion from this species. The epidemiology of toxoplasmosis in goats has not been exhaustively studied in Italy. The lack of studies involving the caprine milk as a potential source of toxoplasmosis transmission in this country highlights the importance of studying this species milk. The present study aimed to determine (a) the seroprevalence of T. gondii infection, (b) the occurrence of T. gondii DNA in blood and milk samples as an indication of the risk of excretion of the parasite in milk, and (c) the genotyping of T. gondii in a population of goats in Italy.

\section{Materials and Methods}

2.1. Animal Population Examined. Between April and May 2012, 127 adult (age $\geq 1 \mathrm{yr}$ ) lactating Chamoisee (Shamwahzay) brown goats were included in the study. The animals were from 6 (I to VI) randomly selected goat farms in the province of Massa-Carrara $\left(44^{\circ} 2^{\prime} 0^{\prime \prime} \mathrm{N} 10^{\circ} 8^{\prime} 0^{\prime \prime} \mathrm{E}\right)$ in Tuscany, Central Italy. They included 59 subjects in farm I, 20 in farm II, 15 in farm III, 13 in farms IV and V, and 7 in farm VI. The animals examined represented the total number of goats within each herd, were raised for milk production, and were kept in extensive breeding with grazing all over the year.

2.2. Blood, Serum, and Milk Sampling. Approximately $10 \mathrm{~mL}$ of blood was collected from the jugular vein of each animal into Vacutainer tubes with and without EDTA. Samples with EDTA were immediately stored and kept under refrigeration until arrival at the laboratory and further processing for the blood nested-PCR (n-PCR) procedure within 24-48 hours. Blood samples without anticoagulant were allowed to clot at room temperature for approximately 15 to 30 minutes. After samples were completely clotted, the sera were separated and kept under refrigeration until arrival at the laboratory, where they were further processed for serological examination within 24-48 hours. Concomitantly with the blood and serum collection, milk was also individually collected from all goats by manual milking of all teats using gloves during manipulation. Before collection, the teats were accurately cleansed with iodine alcohol. From the total quantity of milk each goat produced by manual milking, an aliquot of $50 \mathrm{~mL}$ was individually collected in a sterile centrifuge tube. Milk aliquots were then stored and kept under refrigeration until arrival at the laboratory, where they were stored at $-80^{\circ} \mathrm{C}$.

2.3. Serological Examination. Serum samples were examined for anti-T. gondii IgG antibodies via the modified agglutination test (MAT) using a commercial kit (Toxoscreen DA, Biomérieux, Lyon, France) in accordance with the manufacturer's instructions, and starting at a 1/20 dilution. Sera showing an agglutination titer of $1 / 20$ or higher were considered positive and were end-titrated using 2 -fold dilutions. The choice of this threshold value was a slight modification of a method previously described [16], to satisfy laboratory requirements.

2.4. DNA Extraction. After results of serological tests were known, blood and milk samples from seropositive goats were processed for DNA extraction and subsequent amplification by n-PCR while samples from seronegative goats were discarded. Milk contains minor amounts of nucleated cell in comparison to whole blood, so, after thawing at room temperature and prior to extraction of DNA, a concentration of milk samples was carried out by centrifuge at $2200 \mathrm{~g}$ for $5^{\prime}$ as reported by other authors [17]. To avoid interference by casein, $1 \mathrm{~mL}$ of pellet was treated with $200 \mu \mathrm{L}$ TE $(1 \mathrm{mM}$ EDTA, $10 \mathrm{mM}$ Tris- $\mathrm{HCl}(\mathrm{pH}=7.6))$ and $300 \mu \mathrm{L} 0.5 \mathrm{M}$ EDTA $(\mathrm{pH}=8)$, resuspended and centrifuged at $3000 \mathrm{~g}$ for $10^{\prime}$, as previously reported [18]. Milk samples were then diluted in $200 \mu \mathrm{L}$ of PBS. DNA was extracted from samples of both blood and milk using the QIAamp DNA minikit (Qiagen, Milan, Italy) in accordance with the manufacturer's instructions. After extraction, DNA was stored at $-20^{\circ} \mathrm{C}$ until use.

2.5. Nested PCR. The n-PCR assay used to screen blood and milk samples for $T$. gondii DNA has previously been described [19]. Nested-PCR generally has a risk of crosscontamination from genomic DNA. In order to detect such cross-contamination in PCR and DNA extraction reagents, a negative control was added every 10 samples processed. Negative controls were prepared when DNA from samples analyzed was added to the master mix. They were prepared as separate samples where aliquots of sterile water were added to master mix and contained every reagent with the exception of the template DNA. Negative control reactions were setup and amplified identically to the n-PCR and performed alongside each assay.

2.6. Genetic Characterization of T. gondii Isolates from Goats. Direct genotypic characterization of $T$. gondii strains was performed by PCR amplification of 11 genetic markers (SAG1, 3-SAG2, alt. SAG2, SAG3, BTUB, GRA6, C22-8, C29-2, L358, $\mathrm{PK} 1$, and Apico) and thereafter was analyzed by restriction fragment-length polymorphism, as described by other authors [20].

2.7. Statistical Analysis. Prevalence values were calculated as number of positive animals/number of examined animals $\times$ 100 with the corresponding 95\% confidence intervals (95\% CI). Kappa coefficient was used as a measure of agreement 
between blood n-PCR and milk n-PCR. The following ranges were considered for interpretation of the kappa coefficient: poor agreement $=$ less than 0.00 , slight agreement $=0.00-$ 0.20 , fair agreement $=0.21-040$, moderate agreement $=0.41-$ 0.60 , substantial agreement $=0.61-0.80$, and almost perfect agreement $=0.80-1.00$.

\section{Results}

3.1. Serological Prevalence. Seropositive goats were found in all 6 farms. Overall, 77 out of 127 (60.6\% [95\% CI: 52.169.1\%]) goat serum samples scored positive to MAT for antiToxoplasma IgG. In particular, prevalence values in single farms in decreasing order were as follows: 42/59 (71.2\% [59.6$82.7 \%])$ in farm $\mathrm{I}, 8 / 13$ (61.5\% [35.1-88\%]) in farm V, 4/7 (57.1\% [20.5-93.8\%]) in farm IV, 10/20 (50\% [28.1-71.9\%]) in farm VI, 7/15 (46.7\% [21.4-71.9\%]) in farm II, and 6/13 (46.1\% [19-73.2\%]) in farm III. Anti-Toxoplasma Ig titers ranged from $1: 20$ to $1: 163840$ in farm $\mathrm{I}, 1: 20$ to $1: 80$ in farm II, $1: 40$ to $1: 1280$ in farm III, $1: 40$ to $1: 640$ in farm IV, $1: 20$ to $1: 1280$ in farm V, and $1: 20$ to $1: 160$ in farm VI. Despite of these serological results, there was no clinical evidence of toxoplasmosis in the infected goats at the time of sampling.

3.2. Molecular Detection in Blood and Milk. Among seropositive goats $(n=77)$, the $n$-PCR assay gave positive results on blood samples in 10 of them. The kappa coefficient for the association between results of n-PCR on blood samples and results of n-PCR on milk samples was 1 . Therefore, there was a perfect level of agreement between the two n-PCR assays in all 10 animals, indicating that $13 \%$ (5.5-20.5\%) of seropositive goats and $100 \%$ of those testing positive to n-PCR on blood were excreting T. gondii DNA in their milk. Antibody titers in these goats were $1: 10240(n=2), 1: 2560(n=1), 1: 640$ $(n=1), 1: 320(n=1), 1: 160(n=1), 1: 80(n=2)$, or $1: 20$ $(n=1)$. As none of the negative controls were positive, we concluded that contamination of the master mix and DNA extraction reagents had not occurred.

3.3. Genotyping. Genetic characterization of DNA isolates revealed the occurrence of genotype III from 7 samples, genotype I from one sample, and atypical genotypes with hints for genotype I from 2 samples, as shown in Table 1.

\section{Discussion}

Studies on natural infections in dairy animals are important since they report what has actually occurred in farms. Our results show that exposure of dairy goats to T. gondii infection in the geographic area examined may be very common, since an overall prevalence of $60.6 \%$ as well as prevalence values from $46.7 \%$ to $71.2 \%$ in single farms were detected by MAT. Supposedly, goats acquired Toxoplasma infection on pastures. Thus, it can be hypothesized that the caprine population screened in this survey had relatively high chance to come into contact with infective $T$. gondii oocysts due to high environmental pressure. Data on the prevalence of toxoplasmosis in goat populations during 1990-1999 have been reviewed, with values reaching up to $92 \%$ in many regions of the world and ranging from 19\% to 77\% in Europe [9]. In Italy, a large-scale serological screening in goat farms showed that $5.6 \%$ and $12.3 \%$ of goats had IgM or Ig G antibodies specific to T. gondii [21]. Among abortion samples, T. gondii DNA was detected in $13 \%$ of fetuses and $25 \%$ of placentae from goats [22]. Thus, prevalence values found in this survey fall within those previously reported in the literature for European countries but are considerably higher than previous reports in other geographical areas of Italy. Differences in prevalence values may be dependent on several factors, including density of infected cats shedding oocysts and contaminating the environment, different susceptibility of breed to the infection, rearing conditions, and climatic situation, since oocysts are known to survive longer in moist cool conditions [23].

This survey documents that T. gondii DNA can be present in the milk of naturally infected goats, since DNA was found in 10 milk samples from 77 goats with serology positive to this parasite. PCR methods are considered to lack sensitivity due to the scanty amount of sample used for DNA extraction [24]. In addition, a positive PCR does not demonstrate the presence of viable tachyzoites or cysts containing bradyzoites, since the established reference method for detecting Toxoplasma from foodstuff is gavage or inoculation using either mice or cats. However, we attempted to increase sensitivity by concentration of $50 \mathrm{~mL}$ milk samples. Bioassay is a laborious and time-consuming technique, and it is not suitable for routine monitoring activities on large numbers of samples, also from an animal ethics point of view [25]. Moreover, the occurrence of tachyzoites was reported in the milk of several hosts, including goats $[9,11]$. In particular, the finding and survival of $T$. gondii tachyzoites in goat milk were experimentally studied by Walsh and coworkers [26]. These authors observed that tachyzoites can survive in caprine milk from three to seven days at $+4^{\circ} \mathrm{C}$, thus providing evidence that the raw goat milk can serve as a source of toxoplasmosis. Though tachyzoites are not generally considered as an important source of oral transmission of $T$. gondii because they are rapidly killed outside the host and because they are considered sensitive to proteolytic enzymes, the possibility of infection by tachyzoites penetration of the oral-pharyngeal mucosa has been reported [13]. Tachyzoites were also shown to survive up to $2 \mathrm{~h}$ in pepsin solutions, and adult cats became infected when high numbers of tachyzoites were given orally [11]. Moreover, a recent work showed that DNA of viable T. gondii was present in $10 \%$ of goat milk samples, being able to infect both cell lines and bioassayed cats [27]. Therefore, based on the results of the present survey and on those of other studies, the possibility of Toxoplasma transmission through consumption of raw milk and its unpasteurized derivatives can be hypothesized and have an impact on public health [28].

One of the most important aims of diagnostic tests in animal production is to help to control the introduction of human pathogens into the food chain, including T. gondii. Therefore, the ability of molecular tests as the n-PCR assay to detect goats that are more likely to shed $T$. gondii tachyzoites into their milk is crucial. Based on the results of the present 
TABLE 1: Multilocus genotyping of Toxoplasma gondii isolates from a goat population in Italy.

\begin{tabular}{lcccccccccccc}
\hline \multirow{2}{*}{ Goat no. } & SAG1 & 3'SAG2 & 5'SAG2 $^{\prime}$ & SAG2 new & SAG3 & BTUB & C22-8 & C29-2 & GRA6 & L358 & PK1 & Apico \\
\hline 1 & II/III & I/III & III & III & III & III & III & III & III & NA & III & III \\
2 & II/III & I/III & NA & III & III & III & NA & III & NA & III & NA & III \\
3 & II/III & I/III & III & III & III & III & III & III & NA & NA & III & NA \\
4 & I & I/III & I/II & I & III & NA & I & NA & NA & NA & NA & I \\
5 & II/III & III & III & III & III & NA & III & III & III & NA & III & NA \\
6 & II/III & I/III & I/II & III & NA & III & III & III & NA & III & III & III \\
7 & II/III & I/III & I/II & NA & III & III & NA & III & NA & III & NA & NA \\
8 & I & I/II & III & I & III & NA & I & I & I & NA & NA & III \\
9 & II/III & I/III & I/II & III & III & III & NA & III & NA & III & III & III \\
10 & I & I/III & I/II & I & I & NA & I & I & I & NA & NA & I \\
\hline
\end{tabular}

*NA: not amplified.

survey, goats testing positive to n-PCR on blood samples had positive results also to $n-P C R$ on milk samples in $100 \%$ of the cases $(n=10)$. Consequently, it could be argued that a given $\mathrm{n}$-PCR outcome on blood samples is conclusive as to whether or not a given seropositive goat is shedding Toxoplasma DNA into its milk. However, further investigations are needed to confirm the ability of blood n-PCR as indicator of the likelihood of milk shedding of Toxoplasma tachyzoites in dairy goats.

Results of genetic characterization showed that classical clonal type isolates (III and I) were the most commonly found in this survey. As far as we know this is the first report of genotyping of $T$. gondii isolates in goats in Italy. In Europe, the population structure of this cosmopolitan parasite is markedly clonal with a huge predominance of strains belonging to the type II lineage, which accounts for more than 95\% of isolates, both in humans and animals [29-32]. Strains belonging to the type III can be observed in some cases [31], whereas the type I lineage and nonclonal (also called atypical) strains, that do not fit into the three major lineages, are exceptionally found $[33,34]$. In particular, nonclonal strains of $T$. gondii have so far been reported in chickens in Poland [35], in free-ranging arctic foxes (Vulpes lagopus) in the Svalbard Islands [30], in oocysts from domestic cats in Germany [32], and in a captive Bennett's wallaby (Macropus rufogriseus) in Spain [36]. Interestingly, two isolates from Polish chickens were identical to a nonclonal sheep isolate from Uruguay [35]. Knowledge on the prevalence of atypical strains is of paramount importance. Indeed, they have also been isolated in immunocompetent human patients with severe acquired toxoplasmosis $[34,37,38]$, such as the recently described "Amazonian toxoplasmosis" reported in French Guiana [39]. This is characterized by highly pathogenic and atypical strains linked to a neotropical forest-based cycle involving wild cats and their prey [39]. Moreover, there is evidence that atypical strains are more pathogenic in congenital toxoplasmosis than type II strains $[34,38,40]$ and that they can lead to reinfection in pregnant women with a past immunity to type II strains [38]. In our study, the presence of two atypical strains in goats is difficult to explain and their origin remains unknown. Residence abroad or consumption of meat (especially horse meat) from countries where atypical strains are common has been suggested as possible sources of infection for clinical toxoplasmosis in humans [38, 41]. However, the two examined goats were born on the farm and were not fed with protein supplement of animal source. It has been demonstrated that sexual recombination may yield progeny with very different biological characteristics by reshuffling existing alleles between two parents [42]. Therefore, one possible explanation might be that atypical strains had emerged after a recombination event in cats sharing the same area with goats and that caprine infection occurred through the ingestion of sporulated oocysts from food or water contaminated by feces of these cats.

\section{Conclusion}

Toxoplasmosis is a major public health issue and continues to pose a risk to public health due also to its presence in goat milk. Demands of consumers for pathogen-free products have focused the attention of government regulators and food industry on the necessity to have safe, and high-quality products. Commercial sale and/or distribution of raw milk varies among different countries. Nevertheless, unpasteurized dairy products have gained popularity by consumers who say raw milk strengthens the immune system and provides other health benefits, although it is proven that raw goat's milk is a vehicle for pathogen transmission [43]. Toxoplasmosis transmission by unpasteurized milk can represent a significant means of contamination by this agent $[44,45]$. A European multicentre case-control study investigating the sources of Toxoplasma infection in pregnant women corroborated this evidence, reporting that in Lausanne $14 \%$ of infections were attributed to consumption of inadequately processed milk or milk products, whereas the population attributable fraction was up to 5\% [33]. Our results suggest that, when n-PCR positive results on blood samples from seropositive goats are found, the risk of excretion of Toxoplasma tachyzoites in their milk might frequently occur. Potential transmission of $T$. gondii from the goat milk was also reported by other authors $[12-14,26,27]$. Current consumer recommendations to avoid 
drinking raw milk or eating fresh dairy products made from raw milk are consistent with the findings of the present study.

\section{References}

[1] T. Lehmann, P. L. Marcet, D. H. Graham, E. R. Dahl, and J. P. Dubey, "Globalization and the population structure of Toxoplasma gondii," Proceedings of the National Academy of Sciences of the United States of America, vol. 103, no. 30, pp. 11423-11428, 2006.

[2] L. D. Sibley, D. G. Mordue, C. Su, P. M. Robben, and D. K. Howe, "Genetic approaches to studying virulence and pathogenesis in Toxoplasma gondii," Philosophical Transactions of the Royal Society B, vol. 357, no. 1417, pp. 81-88, 2002.

[3] F. Peyron, J. R. Lobry, K. Musset et al., "Serotyping of Toxoplasma gondii in chronically infected pregnant women: predominance of type II in Europe and types I and III in Colombia (South America)," Microbes and Infection, vol. 8, no. 9-10, pp. 2333-2340, 2006.

[4] A. Khan, J. P. Dubey, C. Su, J. W. Ajioka, B. M. Rosenthal, and L. D. Sibley, "Genetic analyses of atypical Toxoplasma gondii strains reveal a fourth clonal lineage in North America," International Journal for Parasitology, vol. 41, no. 6, pp. 645-655, 2011.

[5] D. Ajzenberg, A. L. Bañuls, C. Su et al., "Genetic diversity, clonality and sexuality in Toxoplasma gondii," International Journal for Parasitology, vol. 34, no. 10, pp. 1185-1196, 2004.

[6] J. P. Dubey, Toxoplasmosis in Animals and Humans, CRC Press, New York, NY, USA, 2nd edition, 2010.

[7] Center for Disease Control and Prevention (CDC), "ParasitesToxoplasmosis (Toxoplasma infection)," http://www.CDC.gov/ parasites/npi.html .

[8] J. G. Montoya and O. Liesenfeld, "Toxoplasmosis," The Lancet, vol. 363, no. 9425, pp. 1965-1976, 2004.

[9] A. M. Tenter, "Toxoplasma gondii in animals used for human consumption," Memorias do Instituto Oswaldo Cruz, vol. 104, no. 2, pp. 364-369, 2009.

[10] J. P. Dubey, C. Rajendran, L. R. Ferreira et al., "High prevalence and genotypes of Toxoplasma gondii isolated from goats, from a retail meat store, destined for human consumption in the USA," International Journal for Parasitology, vol. 41, no. 8, pp. 827-833, 2011.

[11] J. P. Dubey, "Advances in the life cycle of Toxoplasma gondii," International Journal for Parasitology, vol. 28, no. 7, pp. 10191024, 1998.

[12] C. A. Chiari and D. P. Neves, "Human toxoplasmosis acquired by ingestion of goat's milk," Memorias do Instituto Oswaldo Cruz, vol. 79, no. 3, pp. 337-340, 1984.

[13] J. J. Sacks, R. R. Roberto, and N. F. Brooks, “Toxoplasmosis infection associated with raw goat's milk," Journal of the American Medical Association, vol. 248, no. 14, pp. 1728-1732, 1982.

[14] L. J. Skinner, A. C. Timperley, D. Wightman, J. M. W. Chatterton, and D. O. Ho-Yen, "Simultaneous diagnosis of toxoplasmosis in goats and goatowner's family," Scandinavian Journal of Infectious Diseases, vol. 22, no. 3, pp. 359-361, 1990.

[15] C. Alvarado-Esquivel, D. Silva-Aguilar, I. Villena, and J. P. Dubey, "Seroprevalence of Toxoplasma gondii infection in dairy goats in Michoacán State, Mexico," Journal of Parasitology, vol. 99, no. 3, pp. 540-542, 2013.

[16] I. G. Garcia-Bocanegra, O. Cabezòn, E. Hernandez, M. S. Martinez-Cruz, A. Martinez-Moreno, and J. Martinez-Moreno,
"Toxoplasma gondii in ruminant species (cattle, sheep and goats) from Southern Spain," Journal of Parasitology, vol. 99, no. 3, pp. 438-440, 2013.

[17] M. A. Murphy, M. R. Shariflou, and C. Moran, "High quality genomic DNA extraction from large milk samples," Journal of Dairy Research, vol. 69, no. 4, pp. 645-649, 2002.

[18] A. Psifidi, C. I. Dovas, and G. Banos, "A comparison of six methods for genomic DNA extraction suitable for PCR-based genotyping applications using ovine milk samples," Molecular and Cellular Probes, vol. 24, no. 2, pp. 93-98, 2010.

[19] C. D. Jones, N. Okhravi, P. Adamson, S. Tasker, and S. Lightman, "Comparison of PCR detection methods for B1, P30, and 18S rDNA genes of T. Gondii in aqueous humor," Investigative Ophthalmology and Visual Science, vol. 41, no. 3, pp. 634-644, 2000.

[20] C. Su, E. K. Shwab, P. Zhou, X. Q. Zhu, and J. P. Dubey, “Moving towards an integrated approach to molecular detection and identification of Toxoplasma gondii," Parasitology, vol. 137, no. 1, pp. 1-11, 2010.

[21] G. Masala, R. Porcu, L. Madau et al., "Survey of ovine and caprine toxoplasmosis by IFAT and PCR assays in Sardinia, Italy," Veterinary Parasitology, vol. 117, no. 1-2, pp. 15-21, 2003.

[22] G. Masala, R. Porcu, C. Daga et al., "Detection of pathogens in ovine and caprine abortion samples from Sardinia, Italy, by PCR," Journal of Veterinary Diagnostic Investigation, vol. 19, no. 1, pp. 96-98, 2007.

[23] A. Bisson, S. Maley, C. M. Rubaire-Akiiki, and J. M. Wastling, "The seroprevalence of antibodies to Toxoplasma gondii in domestic goats in Uganda," Acta Tropica, vol. 76, no. 1, pp. 33$38,2000$.

[24] M. Opsteegh, M. Langelaar, H. Sprong et al., "Direct detection and genotyping of Toxoplasma gondii in meat samples using magnetic capture and PCR," International Journal of Food Microbiology, vol. 139, no. 3, pp. 193-201, 2010.

[25] European Food Safety Authority (EFSA), "Surveillance and monitoring of Toxoplasma in humans, food and animals," The EFSA Journal, vol. 583, pp. 25-64, 2007.

[26] C. P. Walsh, S. E. Hammond, A. M. Zajac, and D. S. Lindsay, "Survival of Toxoplasma gondii tachyzoites in goat milk: potential source of human toxoplasmosis," Journal of Eukaryotic Microbiology, vol. 46, supplement 5, pp. 73S-74S, 1999.

[27] F. S. Dehkordi, E. Rahimi, and R. Abdizadeh, "Detection of Toxoplasma gondii in raw caprine, ovine, buffalo, bovine, and camel milk using cell cultivation, cat bioassay, capture ELISA, and PCR methods in Iran," Foodborne Pathogens and Disease, vol. 10, no. 2, pp. 120-125, 2013.

[28] L. G. Camossi, H. Greca Jr., A. P. F. L. Corrêa et al., "Detection of Toxoplasma gondii DNA in the milk of naturally infected ewes," Veterinary Parasitology, vol. 177, no. 3-4, pp. 256-261, 2011.

[29] D. Ajzenberg, A. Bañuls, M. Tibayrenc, and M. L. Dardé, "Microsatellite analysis of Toxoplasma gondii shows considerable polymorphism structured into two main clonal groups," International Journal for Parasitology, vol. 32, no. 1, pp. 27-38, 2002.

[30] K. W. Prestrud, K. Åsbakk, T. Mørk, E. Fuglei, M. Tryland, and C. Su, "Direct high-resolution genotyping of Toxoplasma gondii in arctic foxes (Vulpes lagopus) in the remote arctic Svalbard archipelago reveals widespread clonal Type II lineage," Veterinary Parasitology, vol. 158, no. 1-2, pp. 121-128, 2008. 
[31] L. Halos, A. Thébault, D. Aubert et al., "An innovative survey underlining the significant level of contamination by Toxoplasma gondii of ovine meat consumed in France," International Journal for Parasitology, vol. 40, no. 2, pp. 193-200, 2010.

[32] D. C. Herrmann, N. Pantchev, G. Vrhovec et al., "Atypical Toxoplasma gondii genotypes identified in oocysts shed by cats in Germany," International Journal for Parasitology, vol. 40, no. 3, pp. 285-292, 2010.

[33] D. Ajzenberg, "Type I strains in human toxoplasmosis: myth or reality?” Future Microbiology, vol. 5, no. 6, pp. 841-843, 2010.

[34] L. Delhaes, D. Ajzenberg, B. Sicot et al., "Severe congenital toxoplasmosis due to a Toxoplasma gondii strain with an atypical genotype: case report and review," Prenatal Diagnosis, vol. 30, no. 9, pp. 902-905, 2010.

[35] J. P. Dubey, L. T. T. Huong, B. W. L. Lawson et al., "Seroprevalence and isolation of Toxoplasma gondii from free-range chickens in Ghana, Indonesia, Italy, Poland, and Vietnam," Journal of Parasitology, vol. 94, no. 1, pp. 68-71, 2008.

[36] X. Fernández-Aguilar, D. Ajzenberg, O. Cabezón et al., "Fatal toxoplasmosis associated with an atypical Toxoplasma gondii strain in a Bennett's wallaby (Macropus rufogriseus) in Spain," Veterinary Parasitology, 2013.

[37] F. De Salvador-Guillouët, D. Ajzenberg, S. Chaillou-Opitz et al., "Severe pneumonia during primary infection with an atypical strain of Toxoplasma gondii in an immunocompetent young man," Journal of Infection, vol. 53, no. 2, pp. e47-e50, 2006.

[38] A. Elbez-Rubinstein, D. Ajzenberg, M. Dardé et al., "Congenital toxoplasmosis and reinfection during pregnancy: case report, strain characterization, experimental model of reinfection, and review," Journal of Infectious Diseases, vol. 199, no. 2, pp. 280285, 2009.

[39] M. Demar, D. Hommel, F. Djossou et al., "Acute toxoplasmoses in immunocompetent patients hospitalized in an intensive care unit in French Guiana," Clinical Microbioliogy and Infection, vol. 18, no. 17, pp. 221-231, 2012.

[40] R. McLeod, K. M. Boyer, D. Lee et al., "Prematurity and severity are associated with Toxoplasma gondii alleles (NCCCTS, 19812009)," Clinical Infectious Diseases, vol. 54, no. 11, pp. 1595-1605, 2012.

[41] C. Pomares, D. Ajzenberg, L. Bornard et al., "Toxoplasmosis and horse meat, France," Emerging Infectious Diseases, vol. 17, no. 7, pp. 1327-1328, 2011.

[42] M. E. Grigg and N. Sundar, "Sexual recombination punctuated by outbreaks and clonal expansions predicts Toxoplasma gondii population genetics," International Journal for Parasitology, vol. 39, no. 8, pp. 925-933, 2009.

[43] S. Basnet, M. Schneider, A. Gazit, G. Mander, and A. Doctor, "Fresh goat's milk for infants: myths and realities a review," Pediatrics, vol. 125, no. 4, pp. e973-e977, 2010.

[44] R. M. Hiramoto, M. Mayrbaurl-Borges, A. J. Galisteo Jr., L. R. Meireles, M. S. Macre, and H. F. Andrade Jr., "Infectivity of cysts of the ME-49 Toxoplasma gondii strain in bovine milk and homemade cheese," Revista de Saude Publica, vol. 35, no. 2, pp. 113-118, 2001.

[45] A. Flatt and N. Shetty, "Seroprevalence and risk factors for toxoplasmosis among antenatal women in London: a reexamination of risk in an ethnically diverse population," European Journal of Public Health, vol. 23, no. 4, pp. 648-652, 2013. 

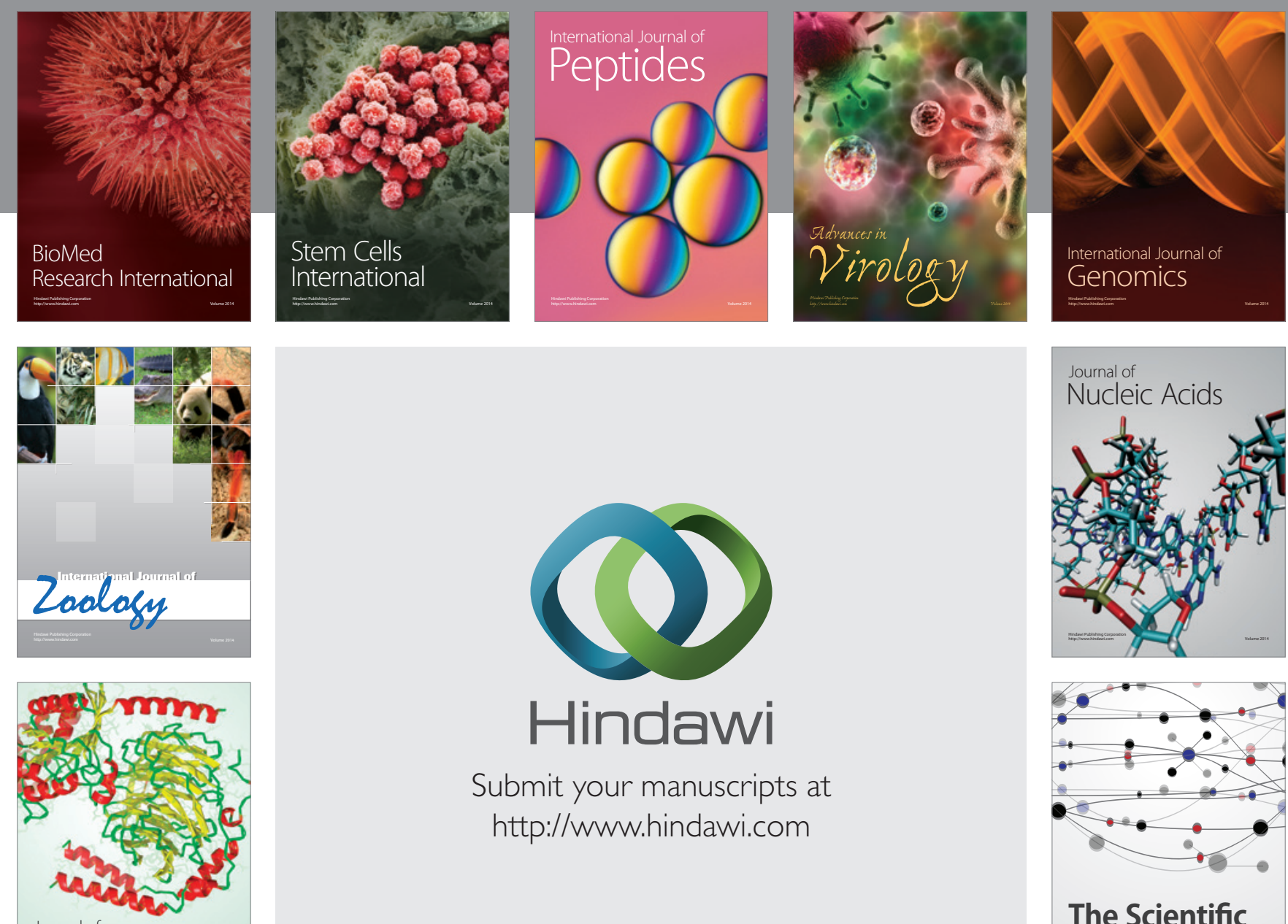

Submit your manuscripts at

http://www.hindawi.com

Journal of
Signal Transduction
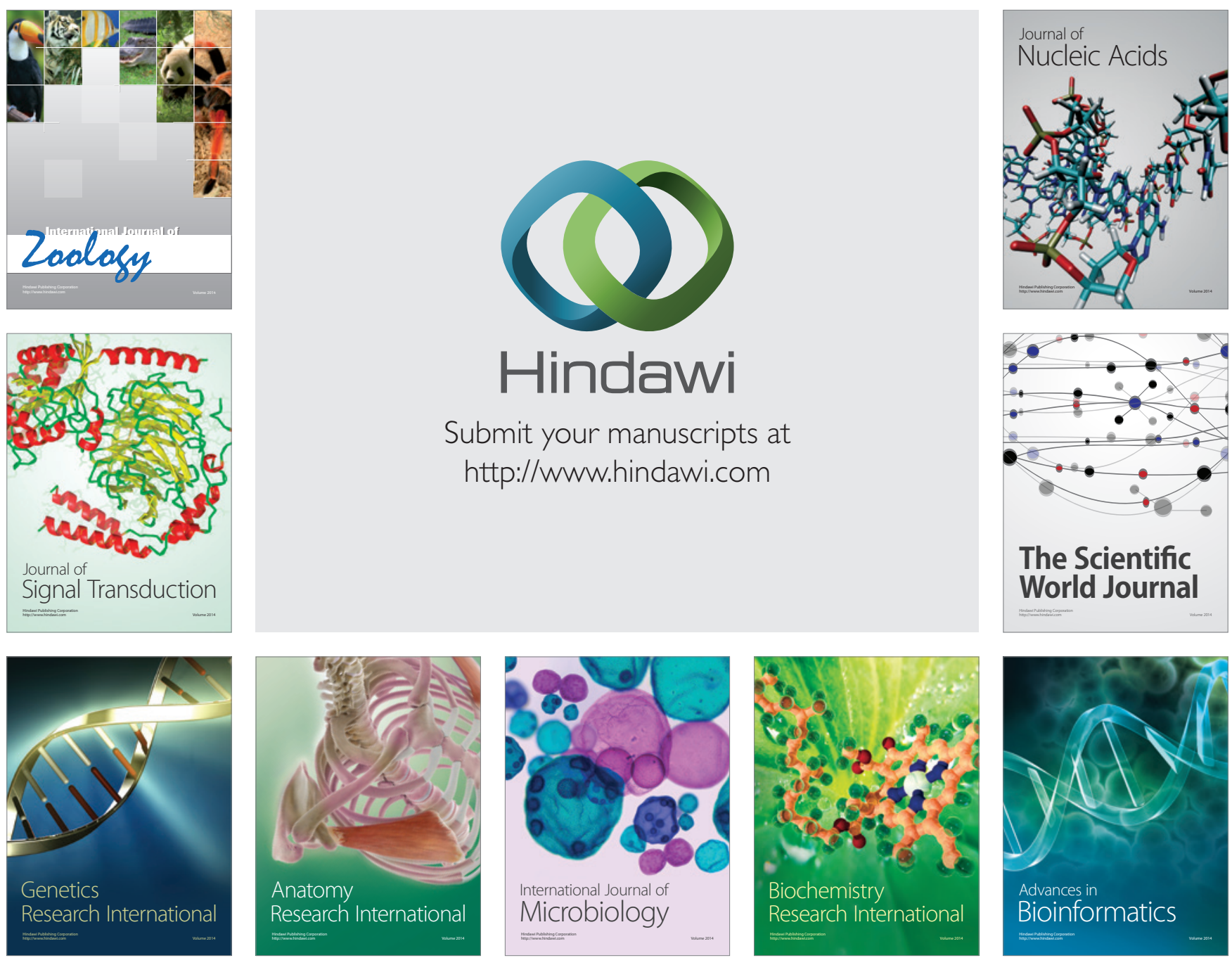

The Scientific World Journal
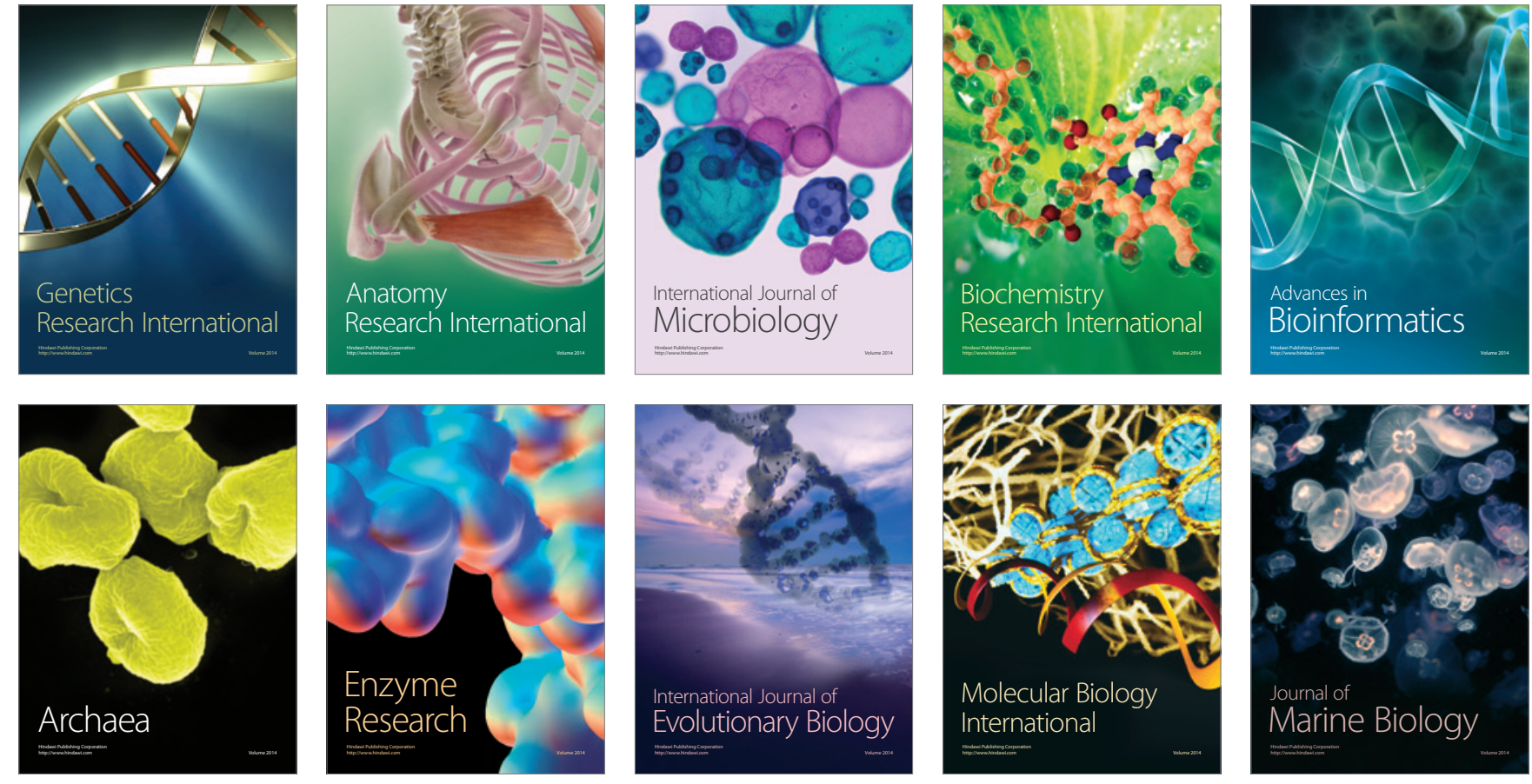